\title{
Hepatic veno-occlusive disease/sinusoidal obstruction syndrome after hematopoietic stem cell transplantation for thalassemia major: incidence, management, and outcome
}

\author{
Xiaoxuan Lai ${ }^{1} \cdot$ Lianjin Liu $^{1} \cdot$ Zhongming Zhang $^{1} \cdot$ Lingling Shi $^{1} \cdot$ Gaohui Yang ${ }^{1} \cdot$ Meiqing $\mathrm{Wu}^{1} \cdot$ Rui Huang $^{1}$ • \\ Rongrong Liu' ${ }^{1}$ Yongrong Lai (i]) ${ }^{1} \cdot$ Qiaochuan Li (i) ${ }^{1}$
}

Received: 5 March 2020 / Revised: 14 January 2021 / Accepted: 28 January 2021 / Published online: 19 February 2021

(c) The Author(s) 2021. This article is published with open access

\begin{abstract}
Hepatic veno-occlusive disease or sinusoidal obstruction syndrome (VOD/SOS) is a potentially life-threatening complication of allogeneic hematopoietic stem cell transplantation (allo-HSCT). In the present prospective study, we aimed to investigate the incidence, management, and outcome of VOD/SOS in patients with thalassemia major (TM) who received allo-HSCT. VOD/SOS was diagnosed and classified based on the modified Seattle criteria. The prophylactic regimen for VOD/SOS was a combination treatment of dalteparin and lipo-PGE1. VOD/SOS was managed through an approach consisting of adequate supportive measures, short-term withdrawal of calcineurin inhibitors (CNIs), and the use of methylprednisolone and basiliximab for graft-versus-host disease prophylaxis. VOD/SOS was found in 54 of 521 patients (10.4\%) at a median time of 12 days after allo-HSCT. The cumulative incidence of all-grade and moderate VOD/SOS was $10.4 \%$ and $4.2 \%$, respectively. Among the $54 \mathrm{VOD} / \mathrm{SOS}$ patients, no patient developed severe grade and died from VOD/SOS. Besides, the cumulative incidence of transplant-related mortality on day 100 for patients with or without VOD/SOS was $0 \%$ vs. $4.0 \%(P=0.187)$, respectively, and the 3-year overall survival rates were $94.3 \%$ vs. $93.2 \%(P=0.707)$, respectively. Collectively, we concluded that appropriate symptomatic therapy and short-term withdrawal of CNIs safely mitigated the mortality of VOD/SOS in TM patients who underwent allo-HSCT.
\end{abstract}

\section{Introduction}

Hepatic veno-occlusive disease/sinusoidal obstruction syndrome (VOD/SOS) is a potentially fatal complication of hematopoietic stem cell transplantation (HSCT). The VOD/ SOS primarily damages both sinusoidal endothelial cells and hepatocytes in zone 3 of the hepatic acinus, and such process is triggered by several factors, such as the toxicity of the conditioning regimen, the release of cytokines due to inflammation and engraftment, and graft-versus-host disease (GvHD) prophylactic regimen [1-3]. The risk factors include thalassemia major (TM), very young or old age, ferritin levels, a history of previous liver disease, conditioning regimen consisting of busulfan $(\mathrm{Bu})$ and

These authors contributed equally: Yongrong Lai, Qiaochuan Li

Qiaochuan Li

liqiaochuan@gxmu.edu.cn

1 Department of Hematology, The First Affiliated Hospital of Guangxi Medical University, Nanning, Guangxi, China cyclophosphamide (Cy), and the use of calcineurin inhibitors (CNIs) for GvHD prophylaxis [4]. The only proved curative therapy of $\mathrm{VOD} / \mathrm{SOS}$ is defibrotide [5].

The only established curative option for TM is allogeneic HSCT (allo-HSCT). It is expected that more than $90 \%$ of TM patients can survive after allo-HSCT with a thalassemiafree survival (TFS) of around 80\% [6]. However, the VOD/ SOS is a common complication of TM patients after alloHSCT, which can probably be attributed to the pre-existing liver damage caused by iron overload, conditioning regimen consisting of $\mathrm{Bu}$ and $\mathrm{Cy}$, and the use of CNIs for GvHD prophylaxis. In this prospective study, we reported the incidence, management, and outcome of VOD/SOS in 521 TM patients who underwent allo-HSCT in our center.

\section{Patients and methods}

\section{Patients}

A total of $521 \mathrm{TM}$ patients were enrolled to assess the VOD/SOS in the present study (Table 1) between July 2007 
Table 1 Main demographic and transplant data of the patients.

\begin{tabular}{|c|c|c|c|}
\hline Characteristics & No-VOD $(N=467)$ & $\operatorname{VOD}(N=54)$ & $P$ value \\
\hline Age-yr & $5(2-19)$ & $5(2-12)$ & 0.256 \\
\hline Male/sex-no. (\%) & $300(64.2)$ & $35(64.8)$ & 0.400 \\
\hline Liver size >5 cm-no. (\%) & $65(13.9)$ & $6(11.1)$ & 0.569 \\
\hline Bilirubin (mg/dL) & $0.7(0.2-2.5)$ & $0.6(0.3-2.3)$ & 0.876 \\
\hline Median serum ferritin (ng/mL) & $3095(465-10,336)$ & $3558(624-11,473)$ & 0.425 \\
\hline Pesaro classification & & & 0.907 \\
\hline Class I-no. (\%) & $72(15.4)$ & $8(14.8)$ & \\
\hline$\geq$ Class II-no. (\%) & 395 (84.6) & $46(85.2)$ & \\
\hline Donor: female for male-no. (\%) & $148(31.7)$ & $20(37.0)$ & 0.993 \\
\hline Donor type & & & 0.433 \\
\hline MSD-no. (\%) & $357(76.4)$ & $37(68.5)$ & \\
\hline URD-no. (\%) & $89(19.1)$ & $14(25.9)$ & \\
\hline Haplotype donor-no. (\%) & $21(4.5)$ & $3(5.6)$ & \\
\hline Cell source & & & 0.310 \\
\hline PBSC-no. (\%) & $90(19.3)$ & $14(25.9)$ & \\
\hline BM-no. (\%) & $15(3.2)$ & 0 & \\
\hline CB-no. (\%) & $8(1.7)$ & $1(1.9)$ & \\
\hline CB + BM-no. (\%) & $158(33.8)$ & $22(42.7)$ & \\
\hline PBSC + BM-no. (\%) & $196(42.0)$ & $17(31.5)$ & \\
\hline ABO incompatibility-no. (\%) & $178(38.1)$ & $26(48.1)$ & 0.153 \\
\hline Infused $\mathrm{MNC}-10^{8} / \mathrm{kg}$ & $12.4(0.5-35.4)$ & $14.3(0.5-31.2)$ & 0.699 \\
\hline Infused $\mathrm{CD} 34^{+}$cells $-10^{6} / \mathrm{kg}$ & $7.5(0.3-32.4)$ & $8.1(0.2-32.9)$ & 0.519 \\
\hline Sepsis post-HSCT-no. (\%) & $64(13.7)$ & $4(7.4)$ & 0.193 \\
\hline No. of platelet transfusions & $4(0-26)$ & $6(1-23)$ & 0.005 \\
\hline $\begin{array}{l}\text { No. of platelet transfusions over } \\
12 \text { days }\end{array}$ & $3(0-10)$ & $4(1-11)$ & 0.096 \\
\hline Platelet refractoriness-no. (\%) & $68(14.6)$ & $9(16.7)$ & 0.680 \\
\hline Days to ANC $>0.5 \times 10^{9} / \mathrm{L}$ & $11(7-32)$ & $12(8-22)$ & 0.585 \\
\hline Days to $\mathrm{PC}>20 \times 10^{9} / \mathrm{L}$ & $14(9-49)$ & $17(9-47)$ & 0.010 \\
\hline Acute GvHD & & & 0.129 \\
\hline Grade I-no. (\%) & $23(4.9)$ & $6(11.1)$ & \\
\hline Grade II-no. (\%) & $50(10.7)$ & $7(13.0)$ & \\
\hline Grade III-no. (\%) & $21(4.5)$ & $1(1.9)$ & \\
\hline Grade IV-no. (\%) & $10(2.1)$ & $3(5.6)$ & \\
\hline Chronic GvHD & & & 0.896 \\
\hline Mild-no. (\%) & $13(2.7)$ & $2(3.8)$ & \\
\hline Moderate-severe-no. (\%) & $11(2.4)$ & $1(1.9)$ & \\
\hline
\end{tabular}

$A N C$ absolute neutrophil count, $B M$ bone marrow, $C B$ cord blood, $G v H D$ graft-versus-host disease, HSCT hematopoietic stem cell transplantation, $M N C$ mononuclear cell, MSD HLA-matched sibling donor, $P B S C$ peripheral blood stem cell, $P C$ platelet count, $U R D$ unrelated donor, $V O D$ hepatic veno-occlusive disease.

and July 2019. These patients received HLA-matched sibling donor (MSD) transplants, unrelated donor (URD) transplants, and haploidentical transplants. This study was approved by the local institutional review board, and the outcome data were reported to the Chinese Bone Marrow Transplant Registry (CBMTR). Written informed consent was obtained from all the parents of the patients following the Declaration of Helsinki. All patients had a Lansky or Karnofsky performance score $\geq 90 \%$. The baseline values of bilirubin, liver size, and body weight before transplantation were determined. The patient characteristics were summarized in Table 1.

\section{Conditioning regimen and GvHD prophylaxis}

The conditioning regimen consisted of $\mathrm{Bu}, \mathrm{Cy}$, fludarabine (Flu), and anti-thymocyte globulin (ATG). The detailed regimen was as follows: (1) $\mathrm{Bu}(1 \mathrm{mg} / \mathrm{kg})$ was intravenously (IV) administered four times per day for 4 days (day -9 to day -6); (2) Flu $\left(50 \mathrm{mg} / \mathrm{m}^{2} /\right.$ day) was IV administered for 3 days (day -12 to day -10$)$; (3) Cy $(50 \mathrm{mg} / \mathrm{kg} /$ day) was IV administered for 4 days (day -5 to day -2 ); and (4) ATG (thymoglobulin, $2.5 \mathrm{mg} / \mathrm{kg} / \mathrm{day}$ ) was IV given for 4 days (days -4 to day -1 ) [7]. GvHD prophylactic regimen for MSD HSCT consisted of cyclosporine A (CsA), methotrexate (MTX), and mycophenolate mofetil (MMF) [8]. GvHD prophylactic regimen for URD HSCT and haploidentical HSCT consisted of tacrolimus, MTX, and MMF.

\section{Diagnosis and classification of VOD/SOS}

VOD/SOS could be diagnosed when two of the following clinical findings presented within 30 days after HSCT according to the modified Seattle criteria [9, 10]: (1) hyperbilirubinemia more than $2 \mathrm{mg} / \mathrm{dL}$; (2) ascites (radiographic examination) and/or unexplained weight gain (2\% above baseline weight); and (3) hepatomegaly over baseline or pain in the right upper quadrant. The severity of VOD/ SOS was defined according to established criteria as follows: mild for clinically manifested VOD/SOS that was resolved without intervention; moderate for VOD/SOS that required treatment but was resolved completely; and severe for VOD/SOS that caused death or progressed to multiorgan failure (MOF). MOF was defined as either an oxygen requirement with an oxygen saturation of $<90 \%$ on room air and/or ventilator dependence; renal insufficiency (doubling of baseline creatinine level and/or dialysis dependence); and/or encephalopathy $[1,10,11]$.

\section{Prophylaxis and management of VOD/SOS}

The prophylactic regimen for VOD/SOS was a combination treatment of dalteparin and lipo-PGE1. Patients were subcutaneously administered with dalteparin at a dose of $100 \mathrm{IU} / \mathrm{kg} /$ day. Lipo-PGE1 was IV infused at a dose of $1 \mu \mathrm{g} / \mathrm{kg} / \mathrm{day}$. Prophylactic therapy consisting of dalteparin and lipo-PGE1 was given until day 21. Once VOD/SOS was clinically diagnosed, standard supportive care measures were adopted, such as the restriction of daily sodium and fluid intake, diuretics, and hematologic support. All patients diagnosed with VOD/SOS were timely administered with dalteparin at a dose of $100 \mathrm{IU} / \mathrm{kg}$, twice daily. CNIs were immediately discontinued for all patients diagnosed with VOD/SOS. The methylprednisolone and anti-CD25 monoclonal antibody (basiliximab) were administered to continue 
the prophylactic or therapeutic regimen of GvHD. After the clinical symptoms of VOD/SOS were improved, CNIs were resumed to continue the prophylactic or therapeutic regimen of GvHD.

\section{Definitions}

The time to VOD/SOS was calculated from the date of HSCT to the date of clinical diagnosis. Neutrophil engraftment and platelet engraftment were defined as the first three consecutive days when the absolute neutrophil count and an unsupported platelet count were $>0.5 \times 10^{9} / \mathrm{L}$ and $>20 \times 10^{9} / \mathrm{L}$, respectively. Platelet refractoriness was defined as a corrected count increment of less than $10,000 / \mu \mathrm{L}$ following at least two sequential fresh platelet transfusions. Transplant-related mortality (TRM) was defined as transplantation-related deaths instead of the recurrence of TM. Overall survival (OS) was defined from the date of transplantation to the date of death or last followup. TFS was defined from the date of transplantation to either the recurrence of transfusion-dependent thalassemia or the death from any cause. Acute and chronic GvHD were classified by Glucksberg and National Institutes of Health classifications $[12,13]$. GvHD-free and relapse-free survival (GRFS) was defined as the absence of relapse, death from any cause, grade 3 to 4 acute GvHD, and chronic GvHD requiring systemic treatment.

\section{Statistical analyses}

The median follow-up time was 38 months, ranging from 1 to 150 months. The primary objective of this study was to determine the cumulative incidence of VOD/SOS and treatment outcome in TM patients. Cumulative incidence estimates were used to determine the incidences of GvHD and VOD/SOS. The probabilities of OS, TFS, and GRFS were evaluated using the Kaplan-Meier method. Results were expressed as a probability or cumulative incidence (\%) with a $95 \%$ confidence interval $(95 \% \mathrm{CI})$. Chi-square statistics was used for discrete variables to compare characteristics of patients, donors, and transplants between groups, and the Mann-Whitney test was employed for continuous variables. Both univariate and multivariate analyses of prognostic factors were carried out according to the log-rank test and a stepwise Cox proportional hazards regression model, respectively. The effects of the following parameters on the development of VOD/SOS were examined: (1) patient characteristics (age, sex, ferritin level, liver size, and risk classification for TM patients), (2) donor characteristics (donor type, female/male donor-recipient combination, cell source, and ABO incompatibility), and (3) transplantation-related factors (development of GvHD, sepsis post-HSCT, and platelet refractoriness). All statistical analyses were performed using SPSS 18.0 software (SPSS, Chicago, IL, USA), except for the cumulative incidence analyses, which were conducted using NCSS software (NCSS, Kaysville, UT, USA).

\section{Results}

\section{Incidence of VOD}

Among the 521 transplants, 54 patients were diagnosed with VOD/SOS at a median time of 12 days (range, 2-43) after HSCT. At diagnosis, 68.5\% (37/54) of SOS/VOD patients had a bilirubin level $<2 \mathrm{mg} / \mathrm{dL}$, and $70.3 \%(38 / 54)$ of VOD/SOS patients had an increased bilirubin level from a baseline value in three consecutive days. Moreover, 41 patients $(75.9 \%)$ had ascites. All VOD/SOS patients had a weight gain $>5 \%$ of the baseline value and hepatomegaly of increased size over pre-HSCT. Retrospectively, all VOD/ SOS patients in this cohort also met the EBMT diagnostic criteria for hepatic SOS/VOD in children and the modified VOD/SOS diagnostic criteria reported by Cairo et al. [1, 2]. The cumulative incidence of all-grade VOD/SOS and moderate VOD/SOS was $10.4 \%$ (95\% CI, 8.9-13.4) and $4.2 \%$ (95\% CI, 2.8-6.4), respectively. The cumulative incidence of moderate VOD/SOS in matched unrelated donor (MUD) HSCT, MSD HSCT, and haploidentical HSCT was $8.7 \%$ (95\% CI, 4.7-16.3), 3.1\% (95\% CI, 1.8-5.4), and 4.2\% (95\% CI, 0.6-28.4), respectively. Moderate VOD/SOS was more frequently detected in MUD HSCT compared with MSD HSCT $(P=0.010)$. No differences in terms of the total number of infused nucleated cells or $\mathrm{CD}_{3} 4^{+}$cells, as well as neutrophil engraftment, were found between patients with or without VOD/SOS. Platelet engraftment was delayed, and the number of platelet transfusions was higher in VOD/SOS patients (Table 1). Univariate analysis revealed that none of the abovementioned factors reached significance for all-grade VOD/ SOS (Table 2).

\section{Treatment and outcome of VOD/SOS}

All VOD/SOS patients received appropriate supportive care, methylprednisolone, and basiliximab for the prophylactic or therapeutic regimen of GvHD, and CNIs were immediately terminated after clinical diagnosis of VOD/ SOS. Among $54 \mathrm{VOD} / \mathrm{SOS}$ patients, mild and moderate VOD/SOS were found in $32(59.3 \%)$ and $22(40.7 \%)$ cases, respectively. No patient developed severe VOD/SOS. All VOD/SOS patients were resolved after a median of 8 days (range, 6-15). After the clinical symptoms of VOD/SOS were improved, CNIs were resumed to continue the prophylactic or therapeutic regimen of GvHD in all VOD/SOS 
Table 2 Univariate analysis of risk factors for the development of VOD.

\begin{tabular}{|c|c|c|c|c|}
\hline Variables & $N$ & $\begin{array}{l}\text { VOD \% } \\
(95 \% \mathrm{CI})\end{array}$ & $\begin{array}{l}\text { Hazard ratio } \\
(95 \% \text { CI })\end{array}$ & $P$ values \\
\hline \multicolumn{5}{|l|}{ Age-yr } \\
\hline$\geq 7 \mathrm{yr}$ & 152 & $8.6(5.1-14.4)$ & 1 & \\
\hline$>4$ and $<7 \mathrm{yr}$ & 177 & $11.0(7.3-16.5)$ & $1.310(0.656-2.616)$ & 0.444 \\
\hline$\leq 4 \mathrm{yr}$ & 192 & $11.3(7.5-17.1)$ & $1.354(0.673-2.721)$ & 0.396 \\
\hline \multicolumn{5}{|l|}{ Pesaro classification } \\
\hline Class I & 80 & $10.1(5.2-19.5)$ & 1 & \\
\hline$\geq$ Class II & 441 & $10.5(8.0-13.7)$ & $1.016(0.480-2.153)$ & 0.996 \\
\hline \multicolumn{5}{|l|}{ Serum ferritin } \\
\hline$>3000 \mathrm{ng} / \mathrm{mL}$ & 270 & $9.3(6.4-13.5)$ & 1 & \\
\hline$\leq 3000 \mathrm{ng} / \mathrm{mL}$ & 251 & $11.6(8.3-16.4)$ & $1.296(0.759-2.213)$ & 0.342 \\
\hline \multicolumn{5}{|l|}{ Donor type } \\
\hline MSD & 394 & $9.4(6.9-12.8)$ & 1 & \\
\hline Haplotype & 24 & $12.5(4.3-36.0)$ & $1.348(0.416-4.373)$ & 0.220 \\
\hline URD & 104 & $13.4(8.4-22.1)$ & $1.469(0.794-2.717)$ & 0.619 \\
\hline \multicolumn{5}{|l|}{ Liver size $>5 \mathrm{~cm}$} \\
\hline Yes & 71 & $8.5(3.9-18.2)$ & 1 & \\
\hline No & 450 & $10.7(8.2-14.0)$ & $1.28(0.548-2.990)$ & 0.569 \\
\hline \multicolumn{5}{|c|}{$\mathrm{ABO}$ incompatibility } \\
\hline No & 317 & $8.9(6.2-12.7)$ & 1 & \\
\hline Yes & 204 & $12.8(8.9-18.3)$ & $1.473(0.864-2.512)$ & 0.155 \\
\hline \multicolumn{5}{|l|}{ Sepsis post-HSCT } \\
\hline Yes & 68 & $6.0(2.3-15.6)$ & 1 & \\
\hline No & 453 & $11.0(8.5-14.4)$ & $1.876(0.678-5.194)$ & 0.226 \\
\hline \multicolumn{5}{|c|}{ Platelet refractoriness } \\
\hline No & 444 & $10.2(7.7-13.4)$ & 1 & \\
\hline Yes & 77 & $11.7(6.3-21.6)$ & $1.150(0.562-2.351)$ & 0.703 \\
\hline
\end{tabular}

HSCT hematopoietic stem cell transplantation, MSD HLA-matched sibling donor, $N$ number of cases, $U R D$ unrelated donor, VOD hepatic veno-occlusive disease.

patients. The median time for short-term withdrawal of CNIs was 8 days, ranging from 7 to 15 days. No patient died from VOD/SOS.

\section{GvHD}

The cumulative incidence of all-grade acute GvHD for patients with or without VOD/SOS was 31.5\% (95\% CI, $21.2-46.7)$ vs. $22.6 \%$ (95\% CI, 19.0-26.7) $(P=0.107)$, respectively, and such value for grade II-IV acute GvHD and grade III-IV acute GvHD was $20.4 \%$ (95\% CI, $12.0-34.5)$ vs. $17.8 \%(95 \% \mathrm{CI}, 14.7-21.7)(P=0.707)$, and 7.4\% (95\% CI, $2.9-19.0)$ vs. $6.7 \%$ (95\% CI, $4.8-9.5)(P=$ $0.845)$, respectively. The cumulative incidence of all-grade chronic GvHD for patients with or without VOD/SOS was $6.2 \%$ (95\% CI, $2.1-18.8)$ vs. $5.9 \%$ (95\% CI, $0.4-8.8)(P=$ $0.956)$, respectively, and such value for moderate-severe chronic GvHD was $2.3 \%$ (95\% CI, $0.4-16.9)$ vs. $2.8 \%$ (95\% CI, 1.6-5.1) $(P=0.731)$, respectively. Eight $(8 / 54$, $14.8 \%$ ) VOD/SOS patients developed acute GvHD after VOD/SOS, and the time for acute GvHD onset was 21 (3-58) days after VOD/SOS. All of the patients with acute

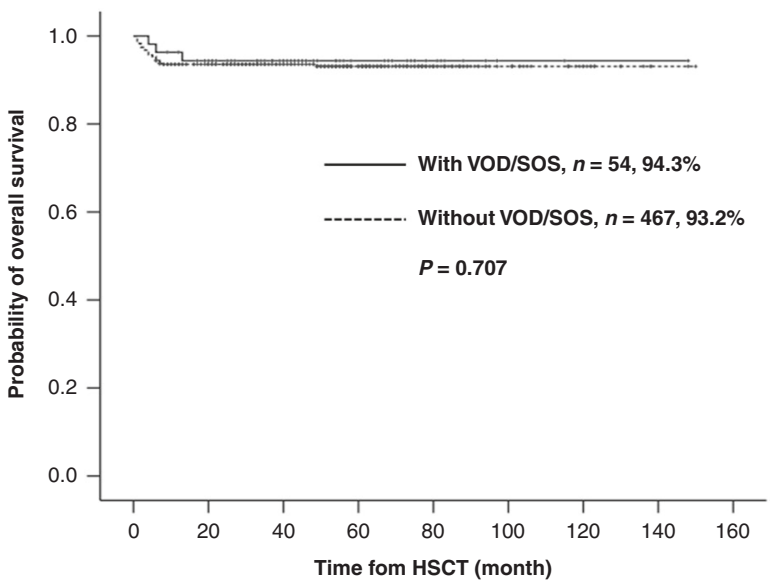

Fig. 1 Probability for overall survival of TM with or without VOD/SOS. Kaplan-Meier probability for OS of TM with or without hepatic VOD/SOS.

GvHD and chronic GvHD favorably responded to immunosuppressive treatment (IST). No one died from GvHD.

\section{Treatment outcome}

Three of $54 \mathrm{VOD} / \mathrm{SOS}$ patients $(5.6 \%)$ died after HSCT, including two deaths due to post-transplant lymphoproliferative disorders, and one death was attributed to interstitial pneumonia. No patients died from VOD/SOS. The cumulative incidence of TRM on day 100 for patients with or without VOD/SOS was $0 \%$ vs. $4.0 \%$ (95\% CI, 2.4-6.5) $(P=0.187)$, respectively. The 3 -year TRM rates were $5.7 \%$ (95\% CI, $1.9-17.0)$ vs. $6.4 \%$ (95\% CI, $4.5-9.1)(P=$ $0.796)$, respectively. The 3 -year OS rates were $94.3 \%(95 \%$ CI, 88.1-100) vs. $93.2 \%$ (95\% CI, 90.9-95.5) $(P=0.707)$, respectively, (Fig. 1). The 3-year TFS rates were $92.5 \%$ (95\% CI, 85.4-99.6) vs. $92.7 \%$ (95\% CI, 90.3-95.1) $(P=$ 0.996), respectively. The 3 -year GRFS rates were $86.9 \%$ (95\% CI, 77.9-96.0) vs. $86.0 \%$ (95\% CI, 82.8-89.2) $(P=$ $0.810)$, respectively.

\section{Discussion}

The incidence of VOD/SOS mainly depends on the patients' status, underlying disease, type of HSCT, conditioning regimen, VOD/SOS prophylactic strategy, and the use of different diagnostic criteria [4]. International Blood and Marrow Transplant Research (CIBMTR) has reported that the incidence of VOD/SOS is $4.9 \%$ in 13,097 patients receiving allo-HSCT [14]. TM is the risk factor of $\mathrm{VOD} / \mathrm{SOS}$, and the incidence of VOD/SOS ranges from $6.1 \%$ to $33 \%$ in TM patients after HSCT [15-17]. Cappelli et al. have reported that oral defibrotide prophylaxis safely reduces the VOD/SOS incidence in pediatric thalassemic 
HSCT recipients [18]. Because defibrotide was not available in our transplant center, the prophylactic regimen for $\mathrm{VOD} / \mathrm{SOS}$ in our study was a combination treatment of dalteparin and Lipo-PGE1. This regimen is commonly used in some centers for VOD/SOS prophylaxis although there is insufficient evidence to support the use of dalteparin and Lipo-PGE1 for VOD/SOS prophylaxis $[19,20]$. In this study, the incidence of VOD/SOS was $10.4 \%$. Such high incidence of VOD/SOS in our study might be attributed to pre-existing liver damage caused by iron overload, conditioning regimen with $\mathrm{Bu}$ and $\mathrm{Cy}$, the use of CNIs for GvHD prophylaxis, and no defibrotide for VOD/SOS prophylaxis. These factors have been reported to be the risk factors for VOD/SOS.

The major risk factors have been identified as follows: elevated ferritin levels, unrelated HSCT, platelet refractoriness, sepsis post-HSCT, young age, conditioning regimens consisting of $\mathrm{Bu}$ and $\mathrm{Cy}$, and the use of CNIs for GvHD prophylaxis [4]. In this study, moderate VOD/SOS was more frequently detected in MUD HSCT (8.7\%) compared with MSD HSCT $(3.1 \%) \quad(P=0.010)$. We found that the platelet engraftment was delayed, and the number of platelet transfusions was higher in VOD/SOS patients, while platelet refractoriness did not reach the significance for all-grade VOD/SOS (Tables 1 and 2). Unlike Cheuk et al., we found that there was no correlation between age and VOD/SOS [21]. Iron overload is prognostically important in HSCT, while we found that there was no correlation between the ferritin levels and VOD/ SOS. Some studies have also shown that there is no correlation between the iron overload and VOD/SOS by using liver biopsy or liver magnetic resonance imaging (R2-MRI) to quantify liver iron content [21-23]. Our findings highlighted that it is necessary to perform prospective studies using direct measurements of iron overload rather than ferritin levels.

Most VOD/SOS fall into the mild or moderate category, and the proportion of severe VOD/SOS is about 25\% [24]. Mild or moderate grade VOD/SOS is usually self-limited and reversible by supportive management. VOD/SOS is fatal in up to $50 \%$ of cases with severe VOD/SOS [24]. Initial reports of the use of defibrotide in the management of VOD show that the resolution rate of VOD is $36-76 \%$, and the day +100 survival is $32-79 \%$ [25-29]. Richardson et al. have reported that earlier defibrotide treatment for VOD/SOS provides more favorable outcomes [30]. Initial reports of the use of methylprednisolone in the management of VOD indicate that the response rate of VOD is $63-67 \%$, and the day +100 survival rate is $58-78 \%[31,32]$. However, defibrotide is not feasible in many transplantation centers. In our study, $59.3 \%$ of VOD/SOS patients were mild, $40.7 \%$ were moderate, and no patient developed severe VOD/SOS or died from VOD/SOS despite the lack of defibrotide in our center. We found that the 3-year OS rates and TFS rates of VOD/SOS patients were $94.3 \%$ and $92.5 \%$, respectively. Our results were better compared with the historical reports, and the short-term withdrawal of CNIs after the early diagnosis of VOD/SOS might contribute to such a good result.

VOD/SOS arises from endothelial cell damage due to the transplantation conditioning regimen [4]. CNIs have damaging effects on the endothelium, leading to the aggravation of VOD/SOS [33]. Short-term withdrawal of CNIs after the diagnosis of VOD/SOS may prevent further deterioration of VOD/SOS. Of course, our results and interpretation should be cautious and need to be validated by further clinical research. On the other hand, the withdrawal of CNIs might increase the risk of GvHD. Our discontinuation of CNIs was short-term, and then CNIs were used again after the clinical symptoms of VOD/SOS were improved. In this study, methylprednisolone and basiliximab were administered to continue the prophylactic or therapeutic regimen of GvHD, which have been proved to be effective in the prophylactic and therapeutic regimen of GvHD [34-36]. In our study, the cumulative incidence of GvHD for patients with VOD/SOS was not significantly higher compared with patients without VOD/SOS, and all GvHD patients favorably responded to IST in this study. The 3-year GRFS rates for patients with or without VOD/ SOS were $86.9 \%$ and $86.0 \%$, respectively $(P=0.810)$. Our therapeutic measures could effectively and safely mitigate the mortality of VOD/SOS.

Collectively, our work showed that allo-HSCT was an effective approach for TM. The incidence of VOD/SOS was still high in TM patients after allo-HSCT. In the present study, we effectively managed VOD/SOS using an approach consisting of adequate supportive measures after the early diagnosis of VOD/SOS, short-term withdrawal of CNIs after the occurrence of VOD/SOS, and the use of methylprednisolone and basiliximab for GvHD prophylaxis. Taken together, this therapeutic strategy could benefit VOD/SOS patients.

Funding This work was financially supported by research grants from National Natural Science of China (Grant No. 81700172; No. 81960038); Scientific Research and Technology Development Program of Guangxi (Grant No. 1598011-1; No. 1140003A-5); and Selfraised Scientific Research Fund of the Ministry of Health of Guangxi Province (Z2014035).

\section{Compliance with ethical standards}

Conflict of interest The authors declare no competing interests.

Publisher's note Springer Nature remains neutral with regard to jurisdictional claims in published maps and institutional affiliations. 
Open Access This article is licensed under a Creative Commons Attribution 4.0 International License, which permits use, sharing, adaptation, distribution and reproduction in any medium or format, as long as you give appropriate credit to the original author(s) and the source, provide a link to the Creative Commons license, and indicate if changes were made. The images or other third party material in this article are included in the article's Creative Commons license, unless indicated otherwise in a credit line to the material. If material is not included in the article's Creative Commons license and your intended use is not permitted by statutory regulation or exceeds the permitted use, you will need to obtain permission directly from the copyright holder. To view a copy of this license, visit http://creativecommons. org/licenses/by/4.0/.

\section{References}

1. Corbacioglu S, Carreras E, Ansari M, Balduzzi A, Cesaro S, Dalle $\mathrm{JH}$, et al. Diagnosis and severity criteria for sinusoidal obstruction syndrome/veno-occlusive disease in pediatric patients: a new classification from the European society for blood and marrow transplantation. Bone Marrow Transplant. 2018;53:138-45.

2. Cairo MS, Cooke KR, Lazarus HM, Chao N. Modified diagnostic criteria, grading classification and newly elucidated pathophysiology of hepatic SOS/VOD after haematopoietic cell transplantation. Br J Haematol. 2020;190:822-36.

3. Mahadeo KM, Bajwa R, Abdel-Azim H, Lehmann LE, Duncan C, Zantek N, et al. Diagnosis, grading, and treatment recommendations for children, adolescents, and young adults with sinusoidal obstructive syndrome: an international expert position statement. Lancet Haematol. 2020;7:e61-72.

4. Corbacioglu S, Jabbour EJ, Mohty M. Risk factors for development of and progression of hepatic veno-occlusive disease/sinusoidal obstruction syndrome. Biol Blood Marrow Transplant. 2019;25:1271-80.

5. Mohty M, Malard F, Abecassis M, Aerts E, Alaskar AS, Aljurf M, et al. Sinusoidal obstruction syndrome/veno-occlusive disease: current situation and perspectives-a position statement from the European Society for Blood and Marrow Transplantation (EBMT). Bone Marrow Transplant. 2015;50:781-9.

6. Angelucci E, Matthes-Martin S, Baronciani D, Bernaudin F, Bonanomi S, Cappellini MD, et al. Hematopoietic stem cell transplantation in thalassemia major and sickle cell disease: indications and management recommendations from an international expert panel. Haematologica. 2014;99:811-20.

7. Li Q, Luo J, Zhang Z, Liu L, Luo L, Yang G, et al. G-CSFmobilized blood and bone marrow grafts as the source of stem cells for HLA-identical sibling transplantation in patients with thalassemia major. Biol Blood Marrow Transplant. 2019;25:2040-4.

8. Lai Y, Ma J, Schwarzenberger P, Li W, Cai Z, Zhou J, et al. Combination of CsA, MTX and low-dose, short-course mycophenolate mofetil for GVHD prophylaxis. Bone Marrow Transplant. 2009;43:61-67.

9. McDonald GB, Sharma P, Matthews DE, Shulman HM, Thomas ED. Venocclusive disease of the liver after bone marrow transplantation: diagnosis, incidence, and predisposing factors. Hepatology. 1984;4:116-22.

10. McDonald GB, Hinds MS, Fisher LD, Schoch HG, Wolford JL, Banaji $\mathrm{M}$, et al. Veno-occlusive disease of the liver and multiorgan failure after bone marrow transplantation: a cohort study of 355 patients. Ann Intern Med. 1993;118:255-67.

11. Jones RJ, Lee KS, Beschorner WE, Vogel VG, Grochow LB, Braine HG, et al. Venoocclusive disease of the liver following bone marrow transplantation. Transplantation. 1987;44:778-83.
12. Glucksberg H, Storb R, Fefer A, Buckner CD, Neiman PE, Clift RA, et al. Clinical manifestations of graft-versus-host disease in human recipients of marrow from HL-A-matched sibling donors. Transplantation. 1974;18:295-304.

13. Jagasia MH, Greinix HT, Arora M, Williams KM, Wolff D, Cowen EW, et al. National Institutes of Health Consensus Development Project on Criteria for Clinical Trials in Chronic Graft-versus-Host Disease: I. The 2014 Diagnosis and Staging Working Group report. Biol Blood Marrow Transplant. 2015;21:389-401.e1.

14. Strouse C, Zhang Y, Zhang MJ, DiGilio A, Pasquini M, Horowitz $\mathrm{MM}$, et al. Risk score for the development of veno-occlusive disease after allogeneic hematopoietic cell transplant. Biol Blood Marrow Transplant. 2018;24:2072-80.

15. Shenoy S, Walters MC, Ngwube A, Soni S, Jacobsohn D, Chaudhury $\mathrm{S}$, et al. Unrelated donor transplantation in children with thalassemia using reduced-intensity conditioning: the URTH trial. Biol Blood Marrow Transplant. 2018;24:1216-22.

16. Sabloff M, Chandy M, Wang Z, Logan BR, Ghavamzadeh A, Li $\mathrm{CK}$, et al. HLA-matched sibling bone marrow transplantation for $\beta$-thalassemia major. Blood. 2011;117:1745-50.

17. Feng Z, Sun E, Lan H, Zhang C, Li Q, Zhu W. Unrelated donor bone marrow transplantation for beta-thalassemia major: an experience from China. Bone Marrow Transplant. 2006;37:171-4.

18. Cappelli B, Chiesa R, Evangelio C, Biffi A, Roccia T, Frugnoli I, et al. Absence of VOD in paediatric thalassaemic HSCT recipients using defibrotide prophylaxis and intravenous Busulphan. Br J Haematol. 2009;147:554-60.

19. Lee SH, Yoo KH, Sung KW, Koo HH, Kwon YJ, Kwon MM, et al. Hepatic veno-occlusive disease in children after hematopoietic stem cell transplantation: incidence, risk factors, and outcome. Bone Marrow Transplant. 2010;45:1287-93.

20. Cheuk DK, Chiang AK, Ha SY, Chan GC. Interventions for prophylaxis of hepatic veno-occlusive disease in people undergoing haematopoietic stem cell transplantation. Cochrane Database Syst Rev. 2015;5:CD009311.

21. Cheuk DK, Wang P, Lee TL, Chiang AK, Ha SY, Lau YL et al. Risk factors and mortality predictors of hepatic veno-occlusive disease after pediatric hematopoietic stem cell transplantation. Bone Marrow Transplant. 2007;40:935-44.

22. Trottier BJ, Burns LJ, DeFor TE, Cooley S, Majhail NS. Association of iron overload with allogeneic hematopoietic cell transplantation outcomes: a prospective cohort study using R2-MRImeasured liver iron content. Blood. 2013;122:1678-84.

23. Armand P, Sainvil MM, Kim HT, Rhodes J, Cutler C, Ho VT, et al. Does iron overload really matter in stem cell transplantation? Am J Hematol. 2012;87:569-72.

24. Bajwa RPS, Mahadeo KM, Taragin BH, Dvorak CC, McArthur J, Jeyapalan A, et al. Consensus report by Pediatric Acute Lung Injury and Sepsis Investigators and Pediatric Blood and Marrow Transplantation Consortium Joint Working Committees: supportive care guidelines for management of veno-occlusive disease in children and adolescents, part 1: focus on investigations, prophylaxis, and specific treatment. Biol Blood Marrow Transplant. 2017;23:1817-25

25. Richardson PG, Soiffer RJ, Antin JH, Uno H, Jin Z, Kurtzberg J, et al. Defibrotide for the treatment of severe hepatic venoocclusive disease and multiorgan failure after stem cell transplantation: a multicenter, randomized, dose-finding trial. Biol Blood Marrow Transplant. 2010;16:1005-17.

26. Richardson PG, Elias AD, Krishnan A, Wheeler C, Nath R, Hoppensteadt D, et al. Treatment of severe veno-occlusive disease with defibrotide: compassionate use results in response without significant toxicity in a high-risk population. Blood. 1998;92: $737-44$. 
27. Richardson PG, Murakami C, Jin Z, Warren D, Momtaz P, Hoppensteadt D, et al. Multi-institutional use of defibrotide in 88 patients after stem cell transplantation with severe veno-occlusive disease and multisystem organ failure: response without significant toxicity in a high-risk population and factors predictive of outcome. Blood. 2002;100:4337-43.

28. Corbacioglu S, Greil J, Peters C, Wulffraat N, Laws HJ, Dilloo D, et al. Defibrotide in the treatment of children with veno-occlusive disease (VOD): a retrospective multicentre study demonstrates therapeutic efficacy upon early intervention. Bone Marrow Transplant. 2004;33:189-95.

29. Bulley SR, Strahm B, Doyle J, Dupuis LL. Defibrotide for the treatment of hepatic veno-occlusive disease in children. Pediatr Blood Cancer. 2007;48:700-4.

30. Richardson PG, Smith AR, Triplett BM, Kernan NA, Grupp SA, Antin $\mathrm{JH}$, et al. Earlier defibrotide initiation post-diagnosis of veno-occlusive disease/sinusoidal obstruction syndrome improves Day +100 survival following haematopoietic stem cell transplantation. Br J Haematol. 2017;178:112-8.

31. Beihany AA, Omar HA, Sahovic E, Chaudhri N, Mohareb FA, Sharif FA, et al. Successful treatment of hepatic veno-occlusive disease after myeloablative allogeneic hematopoietic stem cell transplantation by early administration of a short course of methylprednisolone. Bone Marrow Transplant. 2008;41: 287-91.

32. Myers KC, Lawrence J, Marsh RA, Davies S, Jodele S. High-dose methylprednisolone for veno-occlusive disease of the liver in pediatric hematopoietic stem cell transplantation recipients. Biol Blood Marrow Transplant. 2013;19:500-3.

33. Carmona A, Díaz-Ricart M, Palomo M, Molina P, Pino M, Rovira $\mathrm{M}$, et al. Distinct deleterious effects of cyclosporine and tacrolimus and combined tacrolimus-sirolimus on endothelial cells: protective effect of defibrotide. Biol Blood Marrow Transplant. 2013;19:1439-45.

34. Zeiser R, Blazar BR. Acute graft-versus-host disease - biologic process, prevention, and therapy. N. Engl J Med. 2017;377:2167-79.

35. Ji SQ, Chen HR, Yan HM, Wang HX, Liu J, Zhu PY, et al. AntiCD25 monoclonal antibody (basiliximab) for prevention of graftversus-host disease after haploidentical bone marrow transplantation for hematological malignancies. Bone Marrow Transplant. 2005;36:349-54.

36. Massenkeil G, Rackwitz S, Genvresse I, Rosen O, Dörken B, Arnold R. Basiliximab is well tolerated and effective in the treatment of steroid-refractory acute graft-versus-host disease after allogeneic stem cell transplantation. Bone Marrow Transplant. 2002;30:899-903. 